Please do not cite or distribute without authors' permission.

Word count: 7,491

Running Head: Value-attitude-behaviour model

\title{
A cross-cultural test of the value-attitude-behaviour hierarchy
}

\author{
Taciano L. Milfont \\ Victoria University of Wellington, New Zealand \\ Federal University of Alagoas, Brazil \\ John Duckitt \\ University of Auckland, New Zealand \\ Claire Wagner \\ University of Pretoria, South Africa
}

AUTHORS’ NOTES: Preparation of this manuscript was facilitated by scholarship No. BEX 2246/02-3 from the Ministry of Education of Brazil (CAPES Foundation) to the first author. Correspondence regarding this article should be addresses to Taciano L. Milfont at the School of Psychology, Victoria University of Wellington, PO Box 600, Wellington, New Zealand. Tel.: +64 4463 6398. Fax: +64 4463 5402. Email: taciano.milfont@vuw.ac.nz. 


\begin{abstract}
According to Homer and Kahle's (1988) cognitive hierarchy model, values influence behaviour indirectly through attitudes. The value-attitude-behaviour model therefore implies a hierarchy of cognitions in which the influence theoretically flows from more abstract cognitions (i.e., values) to mid-range cognitions (i.e., attitudes) to specific behaviours. This paper reports findings from a study testing the cross-cultural validity of this model across samples from Brazil, New Zealand and South Africa. Specifically, the aim of the study was to test whether environmental attitudes would fully mediate the influence of both altruistic and self-enhancement values on ecological behaviour. This study also went beyond previous studies by extending the model by including perceived threats from environmental problems. Supporting the expanded value/threat-attitude-behaviour model, a full mediation model was confirmed across countries, in which environmental attitudes fully mediated the influence of values and perceived environmental threat on ecological behaviour. Implications of these findings and of the model as applied to environmental issues are discussed.
\end{abstract}

Keywords: value-attitude-behaviour model, hierarchy, cross-cultural, mediation, environmental attitudes, ecological behaviour 
The study of the relations between values, attitudes, and behaviours are among the most examined topics in social psychology. Homer and Kahle (1988) have tried to integrate the study of the interrelationships between values, attitudes and behaviours by proposing a causal model on the influence between them. Homer and Kahle's model assumes a hierarchical influence of values, attitudes and behaviours. This model has been applied and tested in a variety of areas (Shim, Warrington, \& Goldsberry, 1999; Vaske \& Donnelly, 1999), but only single country studies have been reported thus far. This research set out to tap this gap in the literature by investigating the cross-cultural validity of the model.

\section{Value-attitude-behaviour hierarchy model}

Homer and Kahle's (1988) model assumes the value-attitude-behaviour cognitive hierarchy. According to this model, values influence behaviours both directly and indirectly through attitudes. However, the main feature of this model is its emphasis on the mediating role of attitudes on the values and behaviours relationship. This model therefore implies a hierarchy of cognitions in which the influence theoretically flows from more abstract cognitions (i.e., values) to mid-range cognitions (i.e., attitudes) to specific behaviours. Hence, this model can be visually depicted as a causal sequence: value $\rightarrow$ attitude $\rightarrow$ behaviour.

Homer and Kahle (1988) tested the model in a very specific situation, that is, natural food shopping. Based on the hierarchical model, they proposed that value dimensions influence attitudes toward natural food, which in turn, influence shopping behaviours among natural food consumers. Their findings indicated that values had an influence on attitude toward natural food, and that this attitude had an influence on the purchase of natural food. More importantly, structural equation analysis revealed that 
values had no significant direct influence on shopping behaviours. This result shows that attitudes play a mediating role between values and behaviours, and thus supports the hierarchical model. Although the value-attitude-behaviour cognitive hierarchy model has been applied in order areas, such as to explain career attitude (Shim, Warrington, \& Goldsberry, 1999), this model has been mainly used in research on environmental issues.

\section{Applying the value-attitude-behaviour model to environmental issues}

Homer and Kahle's model has been applied in several theoretical and empirical research related to environmental issues. Studies have used this model to look at either the influence of values on environmental attitudes (EA) and ecological behaviours, or the mediating role of environmental attitudes (see, e.g., Fransson \& Gärling, 1999; Fulton, Manfredo, \& Lipscomb, 1996; Gärling, Fujii, Gärling, \& Jakobsson, 2003; Kaiser \& Scheuthle, 2003; Nordlund \& Garvill, 2002; Stern, Dietz, Abel, Guagnano, \& Kalof, 1999; Stern, Dietz, \& Guagnano, 1995). For instance, Homer and Kahle's model can be identified in Stern's (2000a; Stern, Dietz, \& Guagnano, 1995) well-know theoretical model of ecological behaviour. Stern's model also implies a hierarchical structure, with the major flow of causation from top to bottom (although an upward flow of influence is also likely), and with the strongest causal effects between adjacent variables (see Figure 1).

[Insert Figure 1 about Here]

According to Stern's model social structures (e.g., national laws, market and incentive structures) shape the development of individual's values (e.g., egocentric, altruistic, or ecocentric values), which in turn guide the development of belief systems and worldviews. Belief systems and worldviews represent a general knowledge base from which new attitudes and beliefs about specific environmental issues are formed (e.g., attitudes about recycling, composting, and buying green products). These 
attitudes and beliefs influence behavioural commitments and intentions, which in turn influence ecological behaviour. This model has received empirical support (e.g., Dietz, Stern, \& Guagnano, 1998), and, more recently, Cameron (2002) has conceptually expanded the model by including personal norms, social norms, and action plans, as seen in Figure 1.

In a more explicit test of Homer and Kahle's model as applied to environmental issues, Vaske and Donnelly (1999) examined support for wildland preservation. They found that wildland preservation attitudes entirely mediate the relationship between biocentric/anthropocentric value orientations and wildland preservation voting intention. In another study, Vaske and colleagues (2001) expanded the hierarchical model by exploring the mediating role of value orientations on the relationship between normative beliefs and demographic variables (length of residency, gender, education, and income), that is, demographic variables $\rightarrow$ value orientations $\rightarrow$ normative beliefs $\rightarrow$ behaviour. They found that biocentric/anthropocentric value orientations fully mediate the influence of both income and education on normative belief, and partially mediate the influence of length of residence and gender on normative belief. An inspection of the normative items (e.g., "The amount of human use of national forests should be reduced", "National forests should be managed more for their natural health than for recreation") indicate that their normative belief scale could be seen as an environmental attitudes measure. Hence, their expanded model can be depicted as: demographic variables $\rightarrow$ value orientations $\rightarrow$ EA $\rightarrow$ ecological behaviour.

Another expanded model was proposed by Tarrant, Bright and Cordell (1997). They examined the mediating role of general EA on the relationship between assigned value of the environment and specific attitudes toward wildlife species protection (i.e., 
assigned value $\rightarrow$ general attitude $\rightarrow$ specific attitude). They also tested the moderating role of knowledge of wildlife species protection on the relationship between assigned value and general EA. They tested these models across four wildlife constituent groups: (1) consumptive users (anglers and hunters), (2) non-consumptive users (birders), (3) non-users (non-hunters, non-anglers, and non-birders), and (4) combined consumptive and non-consumptive users (anglers, hunters and birders). The findings indicated that, in general, the mediating role of general EA was supported across all four users groups, and that the moderating role of knowledge was supported for consumptive and consumptive/non-consumptive users groups. However, this study used correlational rather than causal analysis, and the measure used to assess values (i.e., assigned value of the environment) was not an appropriate measure of values as proposed in Homer and Kahle's model, which limits their findings.

A second explicit test of this model as applied to environmental issues was conducted by Grob (1995). In this study, a model in which values affect ecological behaviour directly and indirectly through three attitudinal components was proposed and tested. The three attitudinal aspects considered were the environmental awareness, perceived control and emotional components that correspond to the knowledge, behavioural and affective attitude components. Since this study used attitude theory to develop the dimensions, it is also an example of a theoreticallybased study. Grob's (1995) model predicted 39\% of the respondents' self-reported ecological behaviour. More importantly, his results supported Homer and Kahle's hierarchical value-attitude-behaviour causal sequence by showing that the three attitudinal components mediated the affect of values on ecological behaviour (but values also affected ecological behaviour directly). 
Despite the fact that Homer and Kahle's model includes only value, attitude and behaviour, research has expanded this model by including other variables, such as demographic variables, value orientations, and specific attitudes. It is also likely that this model might be influenced by real social situations. Therefore, in the present research an expanded model is proposed that includes perception of threat from environmental problems.

\section{The role of perceived threat from environmental problems}

In the last two decades many studies have started examining the influence of environmental risk on both EA and ecological behaviour (see, e.g., Axelrod \& Lehman, 1993; Baldassare \& Katz, 1992; Blake, 2001; Bonaiuto, Breakwell, \& Cano, 1996; Covitt, Gomez-Schmidt, \& Zint, 2005; Eisler, Eisler, \& Yoshida, 2003; Harvey \& Belt, 1995; Hine, Marks, Nachreiner, Gifford, \& Health, 2007; Lima, 2004; Lima \& Castro, 2005; Sundblad, Biel, \& Gärling, 2007). This interest in environmental risks seems to have increased specially after a study by Baldassare and Katz (1992) in which they hypothesised that perceived personal threat of environmental problems is a strong predictor of ecological behaviour.

They examined the influence of perceived environmental threat on ecological behaviour by testing whether individuals who believe that environmental problems are a direct threat to their health and wellbeing would be more likely to engage in environmental practices (e.g., limiting the amount of driving to reduce air pollution, or conserving the water used). The results supported their perceived environmental threat hypothesis. They found that perceived personal environmental threat was strongly related to ecological behaviour, and that ecological behaviour was better predicted by perceived environmental threat than by demographic and political variables. 
Furthermore, although some findings have challenged Baldassare and Katz's hypothesis (e.g., Axelrod \& Lehman, 1993; Harvey \& Belt, 1995), research has generally supported the suggestion that perceived environmental threat predicts ecological behaviour (Axelrod \& Lehman, 1993; Lévy-Leboyer, Bonnes, Chase, \& Ferreira-Marques, 1996; Pahl, Harris, Todd, \& Rutter, 2005; Stern, 2000b; Stern, Dietz, Abel, Guagnano, \& Kalof, 1999; Walsh-Daneshmandi \& MacLachlan, 2000). In addition, research has shown that environmental threat also correlate positively and significantly with EA (Pahl, Harris, Todd, \& Rutter, 2005; Walsh-Daneshmandi \& MacLachlan, 2000). Studies have therefore indicated that both EA and ecological behaviour are related to perceptions of real social situations. Environmental problems that become markedly more threatening, or that are at least perceived to do so, seem to shift individuals' concerns and increase ecological behaviour.

In the present research, Homer and Kahle's model is expanded by including perceived environmental threat. It is proposed that perceived environmental threat would influence ecological behaviour indirectly through attitudes. Accordingly, the expanded model suggests that the relationship between both values and perceived environmental and ecological behaviour is mediated by EA. Thus, the expanded model can be depicted as: value/threat $\rightarrow$ attitude $\rightarrow$ behaviour.

A somewhat similar model was recently proposed and tested by Oreg and Katz-Gerro (2006). They included several variables in their model: country-level values (i.e., harmony, and post-materialism), pro-EA (i.e., environmental concern, and perceived threat), perceived behavioural control, willingness to sacrifice for the environment, and behaviour (i.e., recycling, refraining from driving, and environmental citizenship). They also examined individuals' perceptions of environmental threat of two kinds: specific threat under personal control (e.g., air 
pollution by cars) and general threat not under personal control (e.g., air pollution by industry). In their model, willingness to sacrifice mediates the influence of both attitude and perceived behavioural control on behaviour, and both environmental concern and willingness to sacrifice mediates the influence of values on behaviour. Results from structural equation modeling analysis supported this model.

There are, however, two main differences between Oreg and Katz-Gerro's (2006) model and the model proposed here. First, they considered values at a culture level of analysis rather than at an individual level as in the present research. Second, they considered threat as an attitudinal variable, and thus included both threat and EA measures at the same level of analysis. It seems more logical theoretically to consider threat and attitude as distinct constructs (see, e.g., Lai, Brennan, Chan, \& Tao, 2003; Walsh-Daneshmandi \& MacLachlan, 2000). This may explain Oreg and Katz-Gerro’s (2006) inconsistent findings regarding the relationship between threat and willingness to sacrifice. They found that even though the relationship between both types of threat and willingness to sacrifice was significant in their overall sample, this relationship varied across the 38 countries investigated. Had Oreg and Katz-Gerro followed the model proposed in the present research, attitude and threat would be treated as distinct constructs, and the effect of threat on willingness to sacrifice would be examined through EA. Hence, environmental threat would influence willingness to sacrifice indirectly through attitudes. This might have produced more consistent findings across samples in their analyses.

\section{Objectives of the Research}

Homer and Kahle (1988) suggested a causal influence among values, attitudes, and behaviours. The current research aims to assess the cross-cultural validity of Homer and Kahle's model by specifically looking at the mediating role of attitude on 
the relationship between value and behaviour. Their model, with its theoretical premise of the hierarchical influence of values, attitudes and behaviours, has been applied to environmental issues and been found a useful approach to environmental research. Overall, research has shown that values predict EA, and that EA tend to fully mediate the relationship between values and self-reported ecological behaviour. This model is also expanded in this research by including perceived environmental threat, which measures real situations regarding environmental problems. The present research incorporates perceived environmental threat in the model (i.e., value/threat $\rightarrow$ attitude $\rightarrow$ behaviour). This extended model therefore indicates that both values and threat influence attitudes and subsequently behaviour.

It was predicted that the impact of values on behaviour would be entirely mediated by attitudes. Specifically, it was expected that altruistic and selfenhancement would have significant positive and significant negative paths respectively to EA, which in turn would have a significant positive path to ecological behaviour. Altruistic and self-enhancement values were selected because they have been shown to relate to both EA and ecological behaviour (Coelho, Gouveia, \& Milfont, 2006; Milfont \& Gouveia, 2006; Schultz \& Zelezny, 1999). It was predicted that that the impact of perceived threat from environmental problems on ecological behaviour would be entirely mediated by EA.

\section{Method}

\section{Participants}

A questionnaire-based study was conducted in 2005 with undergraduate psychology students from Brazil, New Zealand, and South Africa. The Brazil sample was composed of 201 students (149 females, 52 males) with ages ranging from 18 to 47 years $(M=22.17, S D=4.27)$, the New Zealand sample was composed of 226 
students (159 females, 67 males) with ages ranging from 17 to 39 years $(M=19.48$, $S D=2.54)$, and the South Africa sample was composed of 257 students (187 females, 71 males) with ages ranging from 17 to 42 years $(M=19.36, S D=2.69)$.

\section{Instruments}

The questionnaire was translated into Brazilian-Portuguese and Afrikaans using a bilingual committee approach (van de Vijver \& Leung, 1997). The South African participants were able to choose between an English or Afrikaans version of the questionnaire. Most of the participants $(57.2 \%, n=147)$ chose the English version. The questionnaire included the following measures.

Schwartz Values Survey. A brief inventory containing four 3-item scales (Stern, Guagnano, \& Dietz, 1998) was used to measure Schwartz's (1994) four major value clusters of self-transcendence, self-enhancement, openness to change, and conservatism. Because the self-transcendence cluster is weighted toward environmental content, Stern et al. (1998) created the biospheric and altruistic clusters. The former includes the self-transcendence's environmental items, and the latter includes self-transcendence's non-environmental items. In the present study only two value clusters were examined: altruistic (a world at peace, social justice, and equality), and self-transcendence (protecting the environment, a world at peace, and social justice). These clusters have been shown to relate to both EA and ecological behaviour (Coelho, Gouveia, \& Milfont, 2006; Milfont \& Gouveia, 2006; Schultz \& Zelezny, 1999). The participants rated each value on Schwartz's (1994) 9-point importance scale "as a guiding principle in my life", from -1 (opposed to my values) to 0 (not important) to 7 (of supreme importance). To control for individual differences in response style, centered value scores were calculated by subtracting the 
mean value score (i.e., the average of all 15 value items) from the value clusters (Schwartz, 2005).

Environmental Attitudes Inventory (EAI). This measure is a culture-general and fully-balanced tool developed to measure the multidimensional and hierarchical structure of EA (Milfont \& Duckitt, 2007). The EAI captures both the vertical and horizontal structure of EA by measuring twelve specific facets, or first-order factors, that define the two-dimensional higher order structure of EA (i.e., Preservation and Utilization) (Milfont \& Duckitt, 2004, 2006). For this study a short version of this measure was used (EAI-S). The EAI-S consists of 72 items, with three pro- and three con-trait items for each of the 12 scales (Milfont, 2007). All 42 Preservation items and all 30 Utilization items were computed to form Preservation and Utilization scores. A general environmental attitudes score (i.e., GEA) was also computed by reversing the Utilization items and then averaging responses to all 72 EAI-S items. Examples of the items are: Preservation: "It makes me sad to see forests cleared for agriculture", "I do not believe that the environment has been severely abused by humans" (reverse); Utilization: "Human beings were created or evolved to dominate the rest of nature", "Modern science will NOT be able to solve our environmental problems (reverse)". Responses were given on a 7-point Likert rating scale, ranging from 1 (strongly disagree) to 7 (strongly agree).

Proenvironmental Behaviour Scale. This scale consisted of 8 items previously used by Schultz and colleagues (Schultz \& Zelezny, 1998; Schultz, Zelezny, \& Dalrymple, 2000). Participants were asked to indicate how often they had engaged in each of the eight specific behaviours in the last year on a 5-point scale from 1 (never) to 5 (very often). The behaviours were (1) looked for ways to reuse things, (2) recycled newspaper, (3) recycled cans or bottles, (4) encouraged friends or family to 
recycle, (5) purchased products in reusable or recyclable containers, (6) picked up litter that was not their own, (7) composted food scraps, and (8) conserved gasoline by walking or bicycling. These are, therefore, private-sphere behaviours (Stern, 2000b). Schultz (2001) reported an alpha coefficient of .83 for the full scale (12 items). Ecological behaviour was the term employed to refer to this behavioural measure. Environmental Appraisal Inventory. This 24-item scale was developed by Schmidt and Gifford (1989) to measure hazards in the physical environment across three dimensions: self, environment, and control appraisal. More recently, WalshDaneshmandi and MacLachlan (2000) proposed a version of the scale measuring the self dimension. This adapted version was used in this study and comprises 26 items measuring appraisal of threat to the individual from environmental hazards. However, this inventory also measures the appraisal of threat from environmental hazards that are not directly related to environmental issues (e.g., fluorescent lighting, visual pollution, noise). Thus, only the ten items tapping specific threat from environmental problems (i.e., water pollution, pollution from cars, pollution from factories, pollution from burning rubbish, acid rain, number of people, water shortage, change to the ozone layer caused by pollution, impure drinking water, chemical dumps) were selected and used in the analyses reported. This 10-item version assessing specific perceived threats from environmental problems is refereed to here as the Perceived Environmental Threat scale. Responses were given on a 7-point Likert rating scale, ranging from 1 (no threat) to 7 (extreme threat).

\section{Results}

\section{Descriptive statistics and reliabilities}

Table 1 shows the alpha coefficients, mean inter-item correlations, means and standard deviations for all measures. The only problematic EAI-S scales were Scales 
4 and 7, especially in Brazil and South Africa. The low reliabilities of these scales may be due to the constructs they aim to measure. For instance, Thompson and Barton (1994) also found a low internal reliability ( $\alpha=.58$ in Study 1 , and $\alpha=.67$, in Study

2) for their anthropocentric attitude scale. Using this scale, Schultz and Zelezny (1999) also reported a strong variability of the alpha reliabilities across 14 countries, ranging from .64 to .81 . Thus, the low internal consistency of the Scale 4 may be due to the general aspect of the construct it aims to measure rather than a weakness of the scale per se. This may also be the case for Scale 7. Overall, however, most EAI-S scales showed satisfactory internal reliabilities and homogeneity, with alphas higher than .60 and mean inter-item correlations higher than .15. The low homogeneity of the Preservation, Utilization and GEA scale scores are consistent with their expected multidimensionality. Overall the measures assessing value, threat and behaviour also showed satisfactory internal reliabilities and homogeneity, with alphas close or higher than .60 and mean inter-item correlations higher than .30 .

[Insert Table 1 about Here]

\section{Testing the value-attitude-behaviour hierarchy}

The mediating role of attitude on the values/threat and behaviour relationship was tested through structural equation analyses. The correlations between the Preservation and Utilization latent factors were extremely high in all three countries: Brazil $(\Phi=-.86)$, New Zealand $(\Phi=-.96)$, and South Africa $(\Phi=-.91)$. For this reason, attitude was measure using the EA higher order dimension (i.e., GEA), having the twelve EAI-S scale scores as observed variables. ${ }^{1}$ Value, threat and behaviour were measured with their respective items as observed variables. Our proposed

\footnotetext{
${ }^{1}$ Given that several scholars have proposed that EA are rooted in two higher order sets of environmental values (e.g., Brown \& Cameron, 2000; Stokols, 1990; Wiseman \& Bogner, 2003), Preservation and Utilization factors should be investigated further in future studies.
} 
extended model (i.e., value/threat $\rightarrow$ attitude $\rightarrow$ behaviour) assumes that both value and threat predict attitude. This means that both altruistic and self-enhancement values and perceived environmental threat are important in the formation and determination of EA. Thus, it seems theoretically feasible that values and threat might interact in predicting EA. To discard this option, possible interactions between altruistic values, self-enhancement values and perceived environmental threat were analyzed. Following the procedures outlined by Aiken and West (1991), these three variables were centered and their multiplicative product computed (i.e., altruistic $\times$ self-enhancement, altruistic $\times$ threat, self-enhancement $\times$ threat, and altruistic $\times$ selfenhancement $\times$ threat). The results (not shown) from the hierarchical multiple regression analyses indicated no interactions between altruistic, self-enhancement and environmental problems threat in predicting either EA or ecological behaviour. This means that value and threat are independent predictors of EA. With the possibility that values and perceived threat would interact in predicting EA thus rejected, the mediation model was then tested.

In a first analysis, the factor loadings and the path coefficients between the latent factors were allowed to vary across countries. The overall fit for this unconstrained mediation model was acceptable: $\chi^{2}=4280.38 ; d f=1840 ; \chi^{2} / d f=2.33$; $\mathrm{RMSEA}=.076,90 \% \mathrm{CI}=.073-.079 ; \mathrm{CFI}=.87 ; \mathrm{NNFI}=.87 ; \mathrm{ECVI}=6.75 ; 90 \% \mathrm{ECVI}$ $=6.47-7.04 ; \mathrm{CAIC}=5469.80$. In a second analysis, all parameters were constrained to be equal across groups. This fully constrained full latent variable model showed a significant decrease in model fit, $\chi^{2}(76)=172.68, p<.001$, but had fits virtually identical to the unconstrained model $\left(\chi^{2}=4453.06 ; d f=1916 ; \chi^{2} / d f=2.32 ;\right.$ RMSEA $=$ $.076,90 \% \mathrm{CI}=.073-.079 ; \mathrm{CFI}=.87 ; \mathrm{NNFI}=.87 ; \mathrm{ECVI}=6.78 ; 90 \% \mathrm{ECVI}=6.50-$ 
7.07; CAIC $=5070.36)$. Hence, the completely constrained model was selected as the most parsimonious and adequate mediation model. This model is shown in Figure 2.

[Insert Figure 2 about Here]

The role of both values and perceived threat in the formation and determination of EA was supported by the strong and significant path coefficients from altruistic values $(\beta=.38, p<.001)$, self-enhancement values $(\beta=-.36, p<$ $.001)$, and perceived environmental threat $(\beta=.21, p<.001)$ to EA. Thirty-one percent of the variance of EA could be explained by these three determinants. This model also supported the positive influence of attitude on behaviour as shown by the strong and significant path coefficient $(\beta=.47, p<.001)$ from EA to ecological behaviour. More importantly, the mediating role of EA was supported by the nonsignificant path coefficients between both values and perceived threat and ecological behaviour, but these variables had significant indirect effects on behaviour: altruistic (indirect effect $=.13 ; \mathrm{t}>1.96, p<0.05)$, self-enhancement $($ indirect effect $=-.11 ; \mathrm{t}>$ $1.96, p<0.05$ ), and environmental threat (indirect effect $=.08 ; \mathrm{t}>1.96, p<0.05$ ). This indicates a full mediation model in which the impact of both values and perceived environmental threat on ecological behaviour was entirely mediated by EA.

To further test the mediation model, a country-by-country analysis of this model was conducted (data not shown). Overall, the results from the country-bycountry analysis confirmed the mediating role of EA. However, two different causal patterns were observed in the three countries. First, the explained variance of ecological behaviour varied across countries. The model predicted 25\%, 44\% and $17 \%$ of the respondents' self-reported ecological behaviour in Brazil, New Zealand and South Africa, respectively. Therefore, the model was more suitable in New Zealand. This might indicate that different kinds of threat operate in different social 
contexts, and the environmental threats assessed happened to fit New Zealand best. Another alternative reason is that the research was planned in New Zealand, and the questionnaire was translated into Brazilian-Portuguese and Afrikaans, and it might have been that translations lost certain nuances in items that decreased predictive power. The findings indicate nevertheless that different implications for ecological behaviour prediction were obtained in these three cultures. This suggests that attending to cultural differentiations may be critical to understanding ways in which ecological behaviours are predicted (Milfont, Duckitt, \& Cameron, 2006).

Second, the full mediation model only held for the New Zealand sample. For both the Brazil and South Africa samples, the direct path from altruistic values to ecological behaviour was significant, and the path from perceived threat to ecological behaviour was also significant for the Brazil sample. That is, there was only partial mediation for altruistic in both Brazil and South Africa, and there was also only partial mediation for perceived threat in Brazil. This may indicate that while EA completely mediates the influence of both value and threat on behaviour in some cultures, in others the mediating role of EA is weaker. Nonetheless, it should be noted that one could get full mediation in one model and partial in another due to a rather slight (and nonsignificant) differences between the actual effects. Hence, the findings by and large support the mediating role of EA.

Tables 2 and 3 show respectively the total (i.e., the sum of the direct and mediated indirect effect) and indirect effects of the full latent variable models. As seen in Table 2, the Brazilian sample showed somewhat different results than the other two samples. In Brazil, altruistic had a negative total effect on ecological behaviour and self-enhancement had a positive effect, though not significant. This indicates that in Brazil ecological behaviours seem to be judged in terms of the costs 
or benefits to oneself, activating self-enhancement values. In New Zealand and South Africa, in contrast, such behaviours seem to be judged in terms of the costs or benefits for the community or all humanity, activating altruistic values. This may be a result of Brazil being a poor developing country, where dealing with poverty and economic underdevelopment are major social issues, so that environmental problems are seen in terms of personal interests. However, this is only a speculative explanation. The variation in the direction of the effects in Brazil could have been a result of different interpretations of the value items or even a result of chance. Therefore, this finding needs to be replicated before it can be concluded that it is a robust effect.

[Insert Table 2 and 3 about Here]

A potential alternative model was also tested in which ecological behaviour predicts EA, and the mediating role of ecological behaviour in the value/threatattitude relationship is assumed (i.e., value/threat $\rightarrow$ ecological behaviour $\rightarrow$ EA). This model did not show a significant decrease in model fit $\left(\chi^{2}=4453.07 ; d f=1916\right.$; $\chi^{2} / d f=2.32 ; \mathrm{RMSEA}=.076,90 \% \mathrm{CI}=.073-.079 ; \mathrm{CFI}=.87 ; \mathrm{NNFI}=.87 ; \mathrm{ECVI}=$ $6.78 ; 90 \% \mathrm{ECVI}=6.50-7.07 ; \mathrm{CAIC}=5070.36)$ when compared to the constrained mediation model depicted in Figure 12, and the path coefficient from ecological behaviour to EA was strong and significant $(\beta=.36, p<.001)$. However, all path coefficients between both values and perceived threat and EA were significant. This demonstrates that a mediating role of ecological behaviour can be rejected and accordingly provides additional confirmation for the value/threat $\rightarrow$ attitude $\rightarrow$ behaviour causal model.

\section{Discussion}

This research tested Homer and Kahle's (1988) value-attitude-behaviour cognitive hierarchical model. Our findings support the robustness and generality of 
the value-attitude-behaviour cognitive hierarchical model across cultures. Overall, the impact of altruistic and self-enhancement values on ecological behaviour was fully mediated by EA.

Research has almost uniformly shown the influence of values on both EA and ecological behaviour (e.g., Lévy-Leboyer, Bonnes, Chase, \& Ferreira-Marques, 1996; Milfont \& Gouveia, 2006; Poortinga, Steg, \& Vlek, 2004; Schultz \& Zelezny, 1999; Stern \& Dietz, 1994). Interestingly, however, only a few researchers have conducted studies that explicitly examine the mediating role of EA on the value and behaviour relationship (Grob, 1995; Tarrant, Bright, \& Cordell, 1997; Vaske \& Donnelly, 1999; Vaske, Donnelly, Williams, \& Jonker, 2001). These researchers found, in line with Homer and Kahle's (1988) model, that EA mediate the influence of values on ecological behaviour. The present research provided additional empirical support for this model. The role of altruistic and self-enhancement values in the formation and determination of EA was confirmed, and the impact of these values on ecological behaviour was entirely mediated by EA. For both Brazil and South Africa, however, only partial mediation for altruistic values was supported because altruistic had also direct effects on ecological behaviour.

This research also went beyond previous studies by extending the model to include perceived threats from environmental problems. The expanded model followed from a number of studies showing the influence of perceived threat on EA and ecological behaviour (Axelrod \& Lehman, 1993; Baldassare \& Katz, 1992; Lai, Brennan, Chan, \& Tao, 2003; Lévy-Leboyer, Bonnes, Chase, \& Ferreira-Marques, 1996; Pahl, Harris, Todd, \& Rutter, 2005; Walsh-Daneshmandi \& MacLachlan, 2000). In line with this expanded model, the findings indicated that threat is related to EA, and the inclusion of perceived environmental threat in the model increased the 
proportion of explained variance of EA. Perceived environmental threat explained an additional $4 \%$ of the variance of EA. The findings also supported the expanded model by showing that the impact of threat on ecological behaviours was also entirely mediated by EA. As expected, it was found that the impact of perceived environmental threat on ecological behaviour was entirely mediated by EA, except for Brazil where threat also had a direct impact on ecological behaviour, indicating only partial mediation.

The findings of the present research are limited to cross-sectional survey research and student samples, and thus limited in terms of generalizability. Mayer and Frantz (2004, Study 3) found, for instance, that students from different courses (i.e., environmental studies, chemistry, math, and psychology students) had different scores in their measure of connectedness to nature, with environmental studies students being more connected to nature than their counterparts. This suggests that psychology students may likewise show specificities regarding EA that may limit the generalizability of the findings reported here. However, given that the findings rely more on the diversity of participants' responses on the variables considered than on their socio-demographic characteristics (cf. Kaiser \& Scheuthle, 2003), a certain degree of generalizability seems reasonably likely. The findings of the present study are also limited because they are based only on survey methodologies and on correlational research. Although causal analyses were performed, correlational design was used to examine causal relations in Homer and Kahle's (1988) model. Thus, the findings from this research do not permit causal inference, but the causal relations examined here were theoretically very plausible. Future research should considerer using longitudinal or experimental design to test the actual causalities proposed by the 
model, and also test the model using actual indicators of ecological behaviour rather than self-report scales.

In conclusion, therefore, this research has provided a test of the cross-cultural validity of the value-attitude-behaviour cognitive hierarchy model. Testing this model using SEM analyses across samples from Brazil, New Zealand and South Africa has produced consistent findings.

\section{Reference}

Aiken, L. S., \& West, S. G. (1991). Multiple regression: Testing and interpreting interactions. Newbury Park, CA: Sage.

Axelrod, L. J., \& Lehman, D. R. (1993). Responding to environmental concerns: What factors guide individual action? Journal of Environmental Psychology, 13, 149-159.

Baldassare, M., \& Katz, C. (1992). The personal threat of environmental problems as predictor of environmental practices. Environment and Behavior, 24, 602-616.

Blake, D. E. (2001). Contextual effects on environmental attitudes and behavior. Environment and Behavior, 33, 708-725.

Bonaiuto, M., Breakwell, G. M., \& Cano, I. (1996). Identity processes and environmental threat: The effects of nationalism and local identity upon perception of beach pollution. Journal of Community and Applied Social Psychology, 6, 157-175.

Brown, P. M., \& Cameron, L. D. (2000). What can be done to reduce overconsumption? Ecological Economics, 32, 27-41.

Cameron, L. D. (2002). Promoting positive environmental behaviours through community interventions: A case study of waste minimisation (Environment Waikato Technical Report No. 13). Hamilton: Waikato Regional Council.

Coelho, J. A. P. M., Gouveia, V. V., \& Milfont, T. L. (2006). Valores humanos como explicadores de atitudes ambientais e intenção de comportamento próambiental [Human values as predictors of environmental attitudes and proenvironmental behavior]. Psicologia em Estudo, 11, 199-207.

Covitt, B. A., Gomez-Schmidt, C., \& Zint, M. T. (2005). Exploring environmental issues: Focus on risk. Journal of Environmental Education, 36, 3-13. 
Dietz, T., Stern, P. C., \& Guagnano, G. A. (1998). Social structural and social psychological bases of environmental concern. Environment and Behavior, 30, 450-471.

Eisler, A. D., Eisler, H., \& Yoshida, M. (2003). Perception of human ecology: Crosscultural and gender comparisons. Journal of Environmental Psychology, 23, 89-101.

Fransson, N., \& Gärling, T. (1999). Environmental concern: Conceptual definitions, measurement methods, and research findings. Journal of Environmental Psychology, 19, 369-382.

Fulton, D. C., Manfredo, M. J., \& Lipscomb, J. (1996). Wildlife value orientations: A conceptual and measurement approach. Human Dimensions of Wildlife, 1, 2447.

Gärling, T., Fujii, S., Gärling, A., \& Jakobsson, C. (2003). Moderating effects of social value orientation on determinants of proenvironmental behavior intention. Journal of Environmental Psychology, 23, 1-9.

Grob, A. (1995). A structural model of environmental attitudes and behaviour. Journal of Environmental Psychology, 15, 209-220.

Harvey, M. L., \& Belt, P. A. (1995). The moderating effect of threat on the relationship between population concern and environmental concern. Population and Environment, 17, 123-133.

Hine, D. W., Marks, A. D. G., Nachreiner, M., Gifford, R., \& Health, Y. (2007). Keeping the home fires burning: The affect heuristic and wood smoke pollution. Journal of Environmental Psychology, 27, 26-32.

Homer, P. M., \& Kahle, L. R. (1988). A structural equation test of the value-attitudebehavior hierarchy. Journal of Personality and Social Psychology, 54, 638646.

Kaiser, F. G., \& Scheuthle, H. (2003). Two challenges to a moral extension of the theory of planned behavior: Moral norms and just world beliefs in conservatism. Personality and Individual Differences, 35, 1033-1048.

Lai, C.-1. J., Brennan, A., Chan, H.-m., \& Tao, J. (2003). Disposition toward environmental hazards in Hong Kong Chinese: Validation of a Chinese version of the environmental appraisal inventory (EAI-C). Journal of Environmental Psychology, 23, 369-384. 
Lévy-Leboyer, C., Bonnes, M., Chase, J., \& Ferreira-Marques, J. (1996).

Determinants of pro-environmental behaviors: A five-countries comparison. European Psychologist, 1, 123-129.

Lima, M. L. (2004). On the influence of risk perception on mental health: Living near an incinerator. Journal of Environmental Psychology, 24, 71-84.

Lima, M. L., \& Castro, P. (2005). Cultural theory meets the community: Worldviews and local issues. Journal of Environmental Psychology, 25, 23-35.

Mayer, F. S., \& Frantz, C. M. (2004). The connectedness to nature scale: A measure of individuals feeling in community with nature. Journal of Environmental Psychology, 24, 503-515.

Milfont, T. L. (2007). Psychology of environmental attitudes: A cross-cultural study of their content and structure. Unpublished doctoral dissertation, University of Auckland, Auckland, New Zealand.

Milfont, T. L., \& Duckitt, J. (2004). The structure of environmental attitudes: A firstand second-order confirmatory factor analysis. Journal of Environmental Psychology, 24, 289-303.

Milfont, T. L., \& Duckitt, J. (2006). Preservation and utilization: Understanding the structure of environmental attitudes. Medio Ambiente y Comportamiento Humano, 7, 29-50.

Milfont, T. L., \& Duckitt, J. (2007). The environmental attitudes inventory: A valid and reliable measure to assess the structure of environmental attitudes.Unpublished manuscript.

Milfont, T. L., Duckitt, J., \& Cameron, L. D. (2006). A cross-cultural study of environmental motive concerns and their implications for proenvironmental behavior. Environment and Behavior, 38, 745-767.

Milfont, T. L., \& Gouveia, V. V. (2006). Time perspective and values: An exploratory study of their relations to environmental attitudes. Journal of Environmental Psychology, 26, 72-82.

Nordlund, A. M., \& Garvill, J. (2002). Value structures behind proenvironmental behavior. Environment and Behavior, 34, 740-756.

Pahl, S., Harris, P. R., Todd, H. A., \& Rutter, D. R. (2005). Comparative optimism for environmental risks. Journal of Environmental Psychology, 25, 1-11. 
Poortinga, W., Steg, L., \& Vlek, C. (2004). Values, environmental concern, and environmental behavior: A study into household energy use. Environment and Behavior, 36, 70-93.

Schmidt, F. N., \& Gifford, R. (1989). A dispositional approach to hazard perception: Preliminary development of the environmental appraisal inventory. Journal of Environmental Psychology, 9, 57-67.

Schultz, P. W., \& Zelezny, L. C. (1998). Values and proenvironmental behavior: A five-country survey. Journal of Cross-Cultural Psychology, 29, 540-558.

Schultz, P. W., \& Zelezny, L. C. (1999). Values as predictors of environmental attitudes: Evidence for consistency across 14 countries. Journal of Environmental Psychology, 19, 255-265.

Schultz, P. W., Zelezny, L. C., \& Dalrymple, N. J. (2000). A multinational perspective on the relation between Judeo-Christian religious beliefs and attitudes of environmental concern. Environment and Behavior, 32, 576-591.

Schwartz, S. H. (1994). Are there universal aspects in the structure and contents of human values? Journal of Social Issues, 50, 19-45.

Schwartz, S. H. (2005). Robustness and fruitfulness of a theory of universals in individual human values. In A. Tamayo \& J. Porto (Eds.), Valores e comportamento nas organizações [Values and behavior in organizations] (pp. 56-95). Petrópolis, Brazil: Vozes.

Shim, S., Warrington, P., \& Goldsberry, E. (1999). A personal value-based model of college students' attitudes and expected choice behavior regarding retailing carrers. Family and Consumer Sciences Research Journal, 28, 28-51.

Stern, P. C. (2000a). Psychology and the science of human-environment interactions. American Psychologist, 55, 523-530.

Stern, P. C. (2000b). Toward a coherent theory of environmentally significant behavior. Journal of Social Issues, 56, 407-424.

Stern, P. C., \& Dietz, T. (1994). The value basis of environmental concern. Journal of Social Issues, 50, 65-84.

Stern, P. C., Dietz, T., Abel, T., Guagnano, G. A., \& Kalof, L. (1999). A value-beliefnorm theory of support for social movements: The case of environmentalism. Human Ecology Review, 6, 81-97.

Stern, P. C., Dietz, T., \& Guagnano, G. A. (1995). The new ecological paradigm in social-psychological context. Environment and Behavior, 27, 723-743. 
Stern, P. C., Guagnano, G. A., \& Dietz, T. (1998). A brief inventory of values. Educational and Psychological Measurement, 58, 984-1001.

Stokols, D. (1990). Instrumental and spiritual views of people-environment relations. American Psychologist, 45, 641-646.

Sundblad, E.-L., Biel, A., \& Gärling, T. (2007). Cognitive and affective risk judgements related to climate change. Journal of Environmental Psychology, 27, 97-106.

Tarrant, M. A., Bright, A. D., \& Cordell, H. K. (1997). Attitudes toward wildlife species protection: Assessing moderating and mediating effects in the valueattitude relationship. Human Dimensions of Wildlife, 2, 1-20.

Thompson, S. C. G., \& Barton, M. A. (1994). Ecocentric and anthropocentric attitudes toward the environment. Journal of Environmental Psychology, 14, 149-157.

Van de Vijver, F., \& Leung, K. (1997). Methods and data analysis for cross-cultural research. Thousand Oaks, CA: Sage.

Vaske, J. J., \& Donnelly, M. P. (1999). A value-attitude-behavior model predicting wildland preservation voting intentions. Society and Natural Resources, 12, $523-537$.

Vaske, J. J., Donnelly, M. P., Williams, D. R., \& Jonker, S. (2001). Demographic influences on environmental value orientations and normative beliefs about national forest management. Society and Natural Resources, 14, 761-776.

Walsh-Daneshmandi, A., \& MacLachlan, M. (2000). Environmental risk to the self: Factor analysis and development of subscales for the environmental appraisal inventory (EAI) with an Irish sample. Journal of Environmental Psychology, 20, 141-149.

Wiseman, M., \& Bogner, F. X. (2003). A higher-order model of ecological values and its relationship to personality. Personality and Individual Differences, 34, 783 794. 
Table 1. Descriptive scale statistics for the measures in Brazil, New Zealand and South Africa

\begin{tabular}{|c|c|c|c|c|c|c|c|c|c|c|c|c|c|}
\hline \multirow[b]{2}{*}{ Scale } & \multirow[b]{2}{*}{$\begin{array}{c}\text { No. of } \\
\text { items }\end{array}$} & \multicolumn{4}{|c|}{ Brazil } & \multicolumn{4}{|c|}{ New Zealand } & \multicolumn{4}{|c|}{ South Africa } \\
\hline & & $\alpha$ & $r_{\text {mean }}$ & $M$ & $S D$ & $\alpha$ & $r_{\text {mean }}$ & $M$ & $S D$ & $\alpha$ & $r_{\text {mean }}$ & $M$ & $S D$ \\
\hline \multicolumn{14}{|l|}{ EAI-S } \\
\hline 1. Enjoyment of nature & 6 & .82 & .44 & 5.55 & 1.02 & .88 & .55 & 5.25 & 1.18 & .81 & .43 & 5.49 & 1.09 \\
\hline 2. Conservation policies & 6 & .60 & .21 & 6.00 & .75 & .83 & .45 & 5.49 & .98 & .68 & .27 & 5.67 & .88 \\
\hline 3. Environmental activism & 6 & .85 & .48 & 4.93 & 1.03 & .87 & .54 & 4.34 & 1.25 & .86 & .50 & 4.92 & 1.16 \\
\hline 4. Anthropocentric concern & 6 & .44 & .11 & 3.34 & .80 & .53 & .16 & 3.99 & .86 & .55 & .16 & 3.68 & .95 \\
\hline 5. Confidence in Science & 6 & .77 & .36 & 3.87 & 1.00 & .82 & .44 & 3.69 & 1.02 & .77 & .36 & 3.77 & 1.06 \\
\hline 6. Environmental fragility & 6 & .75 & .35 & 5.63 & .87 & .76 & .34 & 4.93 & .84 & .71 & .30 & 5.45 & .84 \\
\hline 7. Altering nature & 6 & .58 & .18 & 4.08 & .86 & .67 & .25 & 4.03 & .89 & .71 & .28 & 4.19 & 1.03 \\
\hline 8. Personal conservation & 6 & .73 & .33 & 5.51 & .86 & .84 & .46 & 5.03 & 1.11 & .77 & .35 & 5.37 & 1.03 \\
\hline 9. Dominance over nature & 6 & .83 & .44 & 2.74 & 1.17 & .86 & .51 & 3.02 & 1.28 & .78 & .37 & 3.29 & 1.24 \\
\hline 10. Utilization of nature & 6 & .67 & .25 & 2.85 & .83 & .78 & .37 & 3.07 & .90 & .67 & .25 & 3.18 & .85 \\
\hline 11. Ecocentric concern & 6 & .66 & .26 & 5.77 & .75 & .71 & .29 & 5.28 & .87 & .67 & .26 & 5.55 & .89 \\
\hline 12. Population growth & 6 & .83 & .44 & 3.69 & 1.20 & .88 & .54 & 3.20 & 1.35 & .83 & .45 & 4.08 & 1.34 \\
\hline Preservation attitudes & 42 & .88 & .16 & 5.30 & .57 & .91 & .20 & 4.79 & .68 & .87 & .14 & 5.22 & .60 \\
\hline Utilization attitudes & 30 & .81 & .13 & 3.38 & .59 & .86 & .17 & 3.56 & .65 & .82 & .13 & 3.62 & .65 \\
\hline GEA & 72 & .90 & .12 & 5.02 & .51 & .93 & .17 & 4.64 & .61 & .90 & .12 & 4.87 & .55 \\
\hline \multicolumn{14}{|l|}{ Other measures } \\
\hline Altruistic values & 3 & .65 & .39 & 5.82 & 1.09 & .63 & .36 & 5.37 & 1.23 & .58 & .32 & 5.65 & 1.14 \\
\hline Self-enhancement values & 3 & .60 & .34 & 2.86 & 1.32 & .60 & .34 & 3.53 & 1.39 & .55 & .29 & 3.88 & 1.39 \\
\hline Perceived environmental threat & 10 & .89 & .46 & 5.36 & .99 & .90 & .48 & 4.58 & 1.19 & .87 & .41 & 4.83 & 1.18 \\
\hline Ecological behaviour & 8 & .79 & .34 & 2.62 & .79 & .73 & .26 & 3.31 & .69 & .66 & .21 & 2.84 & .68 \\
\hline
\end{tabular}

Note. Brazil: $N=201$. New Zealand: $N=226$. South Africa: $N=257 . r_{\text {mean }}=$ mean inter-item correlation. EAI-S = short-form of the Environmental Attitudes Inventory. GEA

$=$ Generalized Environmental Attitudes (i.e., Preservation and Utilization combined). 
Table 2. Standardized total effects for the value/threat-attitude-behaviour full latent variable model

\begin{tabular}{|c|c|c|c|c|}
\hline & $\begin{array}{l}\text { Altruistic } \\
\text { values }\end{array}$ & $\begin{array}{c}\text { Self-enhancement } \\
\text { values }\end{array}$ & $\begin{array}{c}\text { Perceived } \\
\text { environmental } \\
\text { threat } \\
\end{array}$ & $\begin{array}{l}\text { Environmental } \\
\text { attitudes }\end{array}$ \\
\hline \multicolumn{5}{|c|}{$\begin{array}{l}\text { Completely constrained model } \\
\text { across countries }\end{array}$} \\
\hline Environmental Attitudes & $.38 * * *$ & $-.36^{* * *}$ & $.21 * * *$ & - \\
\hline Ecological Behaviour & $.23 * * *$ & -.09 & $.12 *$ & $.47 * * *$ \\
\hline \multicolumn{5}{|l|}{ Brazil } \\
\hline Environmental Attitudes & $.48 * * *$ & $-.18^{*}$ & $.31 * *$ & - \\
\hline Ecological Behaviour & -.13 & .06 & $.45 * * *$ & $.44 * *$ \\
\hline \multicolumn{5}{|l|}{ New Zealand } \\
\hline Environmental Attitudes & $.36^{* * *}$ & $-.25 * * *$ & $.21 * *$ & - \\
\hline Ecological Behaviour & $.32 * *$ & -.11 & .14 & $.66^{* * *}$ \\
\hline \multicolumn{5}{|l|}{ South Africa } \\
\hline Environmental Attitudes & $.27 *$ & $-.44 * *$ & $.16^{*}$ & - \\
\hline Ecological Behaviour & $.30 * *$ & $-.22 *$ & .07 & $.29 * *$ \\
\hline
\end{tabular}

Note. Brazil: $N=201$. New Zealand: $N=226$. South Africa: $N=257$.

$* p<.05,{ }^{* *} p<.01,{ }^{* * *} p<.001$.

Table 3. Standardized indirect effects for the value/threat-attitude-behaviour full latent variable model

\begin{tabular}{llcc}
\hline & $\begin{array}{c}\text { Altruistic } \\
\text { values }\end{array}$ & $\begin{array}{c}\text { Self-enhancement } \\
\text { values }\end{array}$ & $\begin{array}{c}\text { Perceived } \\
\text { environmental } \\
\text { threat }\end{array}$ \\
\hline $\begin{array}{l}\text { Completely constrained model across countries } \\
\quad \text { Ecological Behaviour }\end{array}$ & $.18^{* * *}$ & $-.17^{* * *}$ & $.10^{* * *}$ \\
$\begin{array}{l}\text { Brazil } \\
\quad \text { Ecological Behaviour }\end{array}$ & $.21^{*}$ & $-.08^{*}$ & $.14^{*}$ \\
$\begin{array}{l}\text { New Zealand } \\
\quad \text { Ecological Behaviour }\end{array}$ & $.24^{* *}$ & $-.17^{* *}$ & $.14^{*}$ \\
$\quad \begin{array}{l}\text { South Africa } \\
\quad \text { Ecological Behaviour }\end{array}$ & $.08^{*}$ & $-.13^{*}$ & .05 \\
\hline
\end{tabular}

Note. Brazil: $N=201$. New Zealand: $N=226$. South Africa: $N=257$.

$* p<.05,{ }^{* *} p<.01, * * * p<.001$. 


\section{Figure Captions}

Figure 1. A schematic causal model of the roles of social structure, values, general beliefs, attitudes, and intentions in determining ecological behaviour. Adapted from Stern, Dietz and Guagnano (1995), and Cameron (2002)

Figure 2. Standardized multiple regression for the completely constrained full latent variable model of direct and mediated (through attitudes) effects of values and threat on self-reported behaviour across countries

Note. Brazil: $N=201$. New Zealand: $N=226$. South Africa: $N=257$. To simplify, manifest variables and the paths from latent to manifest variables are not shown. Dotted arrows represent non-significant causal paths $(t<1.96, p>0.05)$. All other coefficients from normal arrows are significant. Arrows without origin indicate the error terms. Model fit is reported in text. 
Figure 1

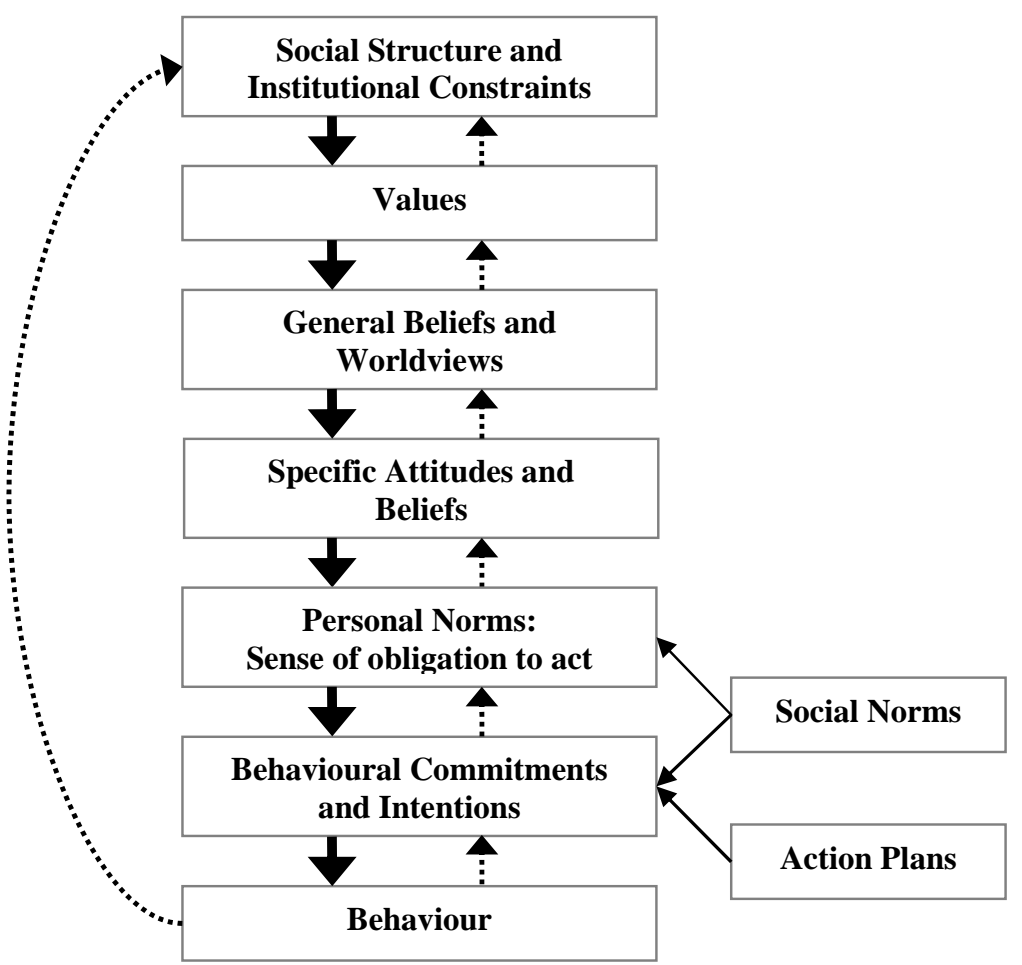

Figure 2

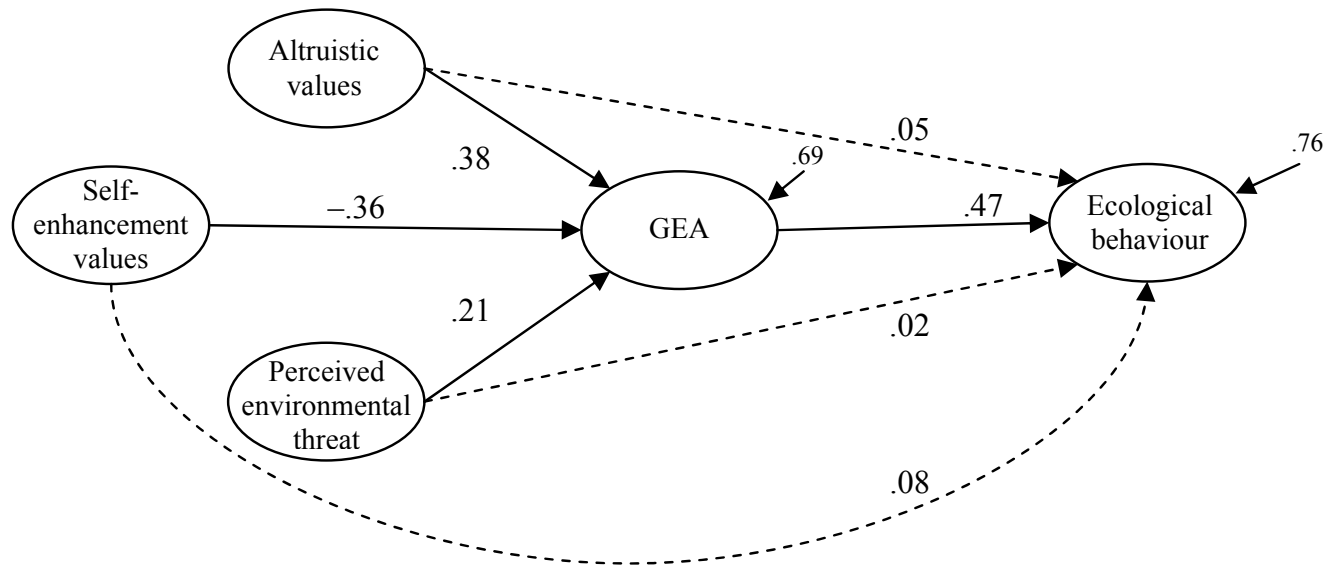

